\title{
Statistical Analysis of Reliability Indices of Ikeja and Port- Harcourt Distribution Systems
}

\author{
Ganiyu Adedayo Ajenikoko ${ }^{1}$, Victor Uchenna Nwagbara ${ }^{2}$ \\ ${ }^{1,2}$ Department of Electronic and Electrical Engineering Ladoke Akintola University of Technology, P.M.B. \\ 4000, Ogbomoso, Nigeria.
}

\begin{abstract}
.
In the evaluation of the reliability levels of electrical power systems, reliability indices play a vital role. These indicators are System Average Interruption Duration Index (SAIDI), System Average Interruption Frequency Index (SAIFI) and Customer Average Interruption Duration Index (CAIDI).

Statistical analysis of reliability indices of Ikeja and Port-Harcourt distribution system was carried out in this research paper.

Ten years of outage data information from ten selected distribution feeders of Ikeja and Port-Harcourt distribution systems were used in this work. The mean and standard deviation of the basic reliability indices were computed using appropriate mathematical relations as input parameters.

Olowu feeder of Ikeja distribution system recorded the highest mean SAIDI of 01040 compared to all other feeders in the selected distribution system. Customers on this feeder were interrupted for a prolonged time while fewer of the customers were adequately served. 7-UP feeder of Ikeja distribution system had the least mean SAIDI of 0.0693 because customers' interruption was for a short period of time even though; more customers were being served by the feeder.

Airport of Port-Harcourt distribution system recorded the highest mean SAIDI of 0.1050. More customers were interrupted compared to all other feeders on the distribution system while fewer of them were adequately served. Airport feeder of Port Harcourt distribution system had a least mean SAIFI of 0.1392 because fewer of the customers attached to this feeder were interrupted while many of them were adequately served.

The result of the work will provide a background information for distribution system engineers for adequate planning and effective maintenance of Ikeja and Portharcourt distribution systems.

Keywords: Statistical analysis, Mean SAIDI, Mean SAIFI, Mean CAIDI, SAIDI standard deviation, SAIFI standard deviation, CAIDI standard deviation.

DOI: $10.7176 /$ APTA/77-06

Publication date:May $31^{\text {st }} 2019$

\section{Introduction.}

Reliability indices are measures of distribution system reliability. The systematic ways of judging the performance of an electrical power system is referred to as reliability indices. They are broadly adopted by many regulatory boards and utilities.

There are three main components of power systems namely: generation, transmission and distribution systems. The generation system produces electricity, transmission system delivers the generated electricity to distribution systems for supplying load demands. Both the generation and transmission systems are called the composite system or the bulk power system (El-Kady et al, 2007; Cyman, 2002, Andreotti et al,2009).

Due to the importance of power quality is to certain customers, many utilities could sell electrical energy at different prices to their customers, depending on the quality of the delivered electric power. Since most end users are connected to secondary distribution networks, at low voltage, it could be important to monitor and compensate the main disturbances on the low voltage grid (Endrenyi and Anders, 2006).

Distributed generation (DG) is defined by the Electric Power Research Institute (EPRI) as a small scale (0.50 MW) energy resource connected directly to the distribution network. Distributed generation has the advantage that, as the population expands and power generation needs change, the transmission network does not require expensive upgrades and extensions, as the generation source can be efficiently taken to the load in a more efficient manner (Billinton and Wang, 1999).

The operation of distribution networks are normally meshed in design and it is nearly always configured radially. Re-configuration consists of changing the network configuration by opening/closing feeders and tie switches so that the networks become radial in operation. The configuring of distribution networks may be modified manually or by automatic switching operations for supplying the loads aiming at minimizing the cost of active power losses. Likewise, reconfiguration may increase system security and power quality (Anderson and Bose 2003).

Maintenance policies play an important role in the reliability of repairable systems because maintenance actions can significantly affect the failure probability of the system. For a complex system, i.e. a unit with a large number of parts, the repair or the substitution of a failed part restores the system performance, but does not generally produce a significant reliability improvement because the conditions of the non-failed parts are left
\end{abstract}


unchanged. In such a case, it is generally assumed that each repair brings the system to condition it was just before failure occurrence (Billinton and Khan, 2008).

Prediction of the future failure behaviour and appropriate maintenance plans entails an accurate reliability analysis (Billinton and Singh, 2004,;Andreotti et al, 2009). Reliability performance of distribution utilities has received considerable attention in recent years (Elena and Vitaly, 2006).

The reliability of power distribution systems is greatly affected by outages caused by different environmental factors on overhead lines. Since animals cause significant number of outages on overhead distribution systems, it is important to investigate these outages (Allen and Bruce,2013).

The main objective of restructuring is to introduce competition in the power industry and to reduce electricity cost to customers. In conventional power systems, electricity prices and system reliabilities are centrally controlled and managed by the system operators. Electricity prices are usually determined by the administration and are fixed for the same type of customers at different locations. In the new deregulated environment, electricity prices vary with time and location which are determined by the power market structures, generation buildings, customer demands, locations and choice on price and reliability (Applebaum,2010). The significant roles of reliability indices in the overall assessment of power quality is also remarkable.

\section{Related Studies}

Billinton (2010) developed a mathematical model for describing the statistical analysis of power distribution network. In his work, he used parameters of the mean and variance of the system reliability indices to establish the correlations between them and other stat istical parameters. The results of the work could be used by power system distribution engineers in formulating maintenance policies for utility companies.

Billinton (2014) illustrated a probabilistic technique to assess the operating reserve requirements in a system. In this approach, the generation system is cla ssified into different system operating states. This technique combines deterministic criteria with probabilistic indices to monitor the system well-being, as designated by deterministic criteria, is identified as being healthy, maginal and at risk. A risk index designated as the Generating System Operating State Risk (GSOSR) is defined as the probability of residing in an undesirable operating state. Farag et al (2008) developed a new probabilistic reliability assessment framework and economic models for reliability planning. A Markov model of the new reliability framework, which is expected to provide a major advancement in the field, is also presented.

Mitra and Singh (2016) incorporated DC load flow model in the decomposition simulation method for multi-area reliability evaluation. State enumeration approach using topological analysis has been used to evaluate bulk power system reliability. System frequency, duration and availability indices have been obtained using topological enumeration. The method requires the use of $\mathrm{AC}$ or DC load flow to test the condition of contingency state.

Nagaraj et al (2014) presented modeling and analysis of distribution reliability indices. In this paper, an efficient Monte Carlo simulation method for distribution system reliability assessment is presented. Analysis of outage data from a practical distribution system is performed to determine the failure and repair models appropriate for use in the Monte Carlo simulation. The sensitivity of the reliability indices to the choice of model is presented. Finally, the impact of protection devices on the statistical distribution of SAIFI for a practical distribution feeder is presented.

\section{Materials and method.}

The statistical models of the failure and repair processes do not affect the average system indices, which can be calculated by analytical methods and depend only on the failure and repair rate averages. The simple HPP model for the failure process leads to fast and easy-to-calculate analytical methods for reliability assessment. System reliability is normally stated in terms of the average values of the relevant reliability indices. The expected value indicates the central tendency of a random variable and is the primary index of system adequacy in most system reliability indices.

\section{Collection of data}

Collection of raw data was done at the national control center (NCC), Osogbo. Ten years of outage information from selected distribution systems on the Nigeria National Grid were also collected from NCC Osogbo.

The data collected from NCC, Osogbo include:

Recorded faults on each of the selected distribution system from the study period.

Recorded outage times on each of the selected distribution system.

Recorded number of customers' served on each of the distribution system.

Recorded number of customers' interruption on each of the distribution systems. 
Statistical analysis was adopted here to determine the mean and Standard Deviation of the system reliability indices: SAIDI, SAIFI and CAIDI.

(i) The system reliability indices - SAIDI, SAIFI and CAIDI were computed.

(a) System Average Interruption Duration Index, SAIDI is given by

SAIDI $=\frac{\text { Customer int erruption durations }}{\text { Total Number of Customers Served }}$

(b) System Average Interruption Frequency Index, SAIFI is given by

$$
\text { SAIFI }=\frac{\text { Total number of customer int erruptions }}{\text { Total Number of Customers Served }}
$$

(c) Customer Average Interruption Duration Index, CAIDI is given by

$$
\text { CAIDI }=\frac{\text { Customer int erruption durations }}{\text { Total Number of Customers Interruption }} \text {. }
$$

ii. The mean values and standard deviations of the system reliability indices were computed.

The mean value $\mu \mathrm{x}$ of a set of $\mathrm{N}$ measured values for the random variables $\mathrm{X}$ is obtained by summing the values and dividing by $\mathrm{N}$.

$$
\mu_{X}=\frac{\sum_{i-1}^{N} X_{i}}{N}
$$

Expected value:

The expected value $\mathrm{E}[\mathrm{X}]$ of the random variable is the mean value obtained if all

Possible values of the random variables were multiplied by their likelihood of occurrence and summed. The mean and expected value are numerically the same.

$$
\begin{aligned}
E[X] & =\mu_{x} \\
& =\int X f(x) d x \\
& =\sum X_{P}\left(X_{i}\right)
\end{aligned}
$$

Where:

$\mathrm{f}(\mathrm{x})=$ probability density function of $\mathrm{X}$

$\mathrm{P}(\mathrm{Xi})=$ probability density function of $\mathrm{Xi}$

Variance:

The variance $\operatorname{Var}[\mathrm{X}]$ of a random variable $\mathrm{X}$ is the expected value of the squared difference between the random and its mean value.

$$
\begin{aligned}
\operatorname{Var}[X]=E\left[\left(X-\mu_{x}\right)^{2}\right] & \\
& =\int\left(X-\mu_{x}\right)^{2} f(x) d x \\
& =\frac{\sum\left[\left(X_{i}-\mu_{x}\right)^{2}\right]}{N}
\end{aligned}
$$

Standard deviation:

To express the scatter or dispersion of a random variable about its expected value in the same unit as the random variable itself, the standard deviation $\sigma \mathrm{x}$ was taken as the square root of the variance. Thus:

$$
\sigma_{x}=\sqrt{\operatorname{Var}[X]}
$$




\section{Discussion of Results.}

\section{Case Study 1: Ikeja Distribution System.}

Figures 1 and 2 show the mean and standard deviation for SAIDI for Ikeja distribution system. The highest mean SAIDI of 0.1040 and a standard deviation of 0.0496 were recorded on Olowu feeder as displayed in the figures.

Olowu feeder experienced a prolonged period of customers' interruption. 7-Up feeder had the least mean SAIDI of 0.0693 with a standard deviation of 0.0371 from the mean. A shorter period of time interruption was experienced by customers served by this feeder.

Alagbole feeder recorded the highest mean SAIFI of 0.2481 with a standard deviation 0.0279 as shown in Figures 3 and 4. .Fewer of the many customers interrupted on this feeder were served adequately. The least mean SAIFI of 0.1887 was recorded on Opebi feeder with a standard deviation of 0.0168 .

Opebi feeder has the highest mean CAIDI of 0.5394 with a standard deviation of 0.2846 even though, the number of customers' interruptions had reduced appreciably as illustrated in Figures 5 and 6 . The least mean CAIDI of 0.3825 and a standard deviation of 0.1891 were recorded on Alagbole feeder.

\section{Case Study 2: Portharcourt Distribution System.}

Figures 7 and 8 displays the mean and standard deviation for SAIDI for Portharcourt distribution system. Airport feeder recorded the highest mean SAIDI of 0.1051 with a standard deviation of 0.0471 as shown in Figures 7 and 8. Customers on this feeder were put in a condition of darkness owing to the prolonged time of interruptions. Michelin feeder had the least mean SAIDI of 0.0695 with a standard deviation of 0.0342 . A shorter period of interruptions is experienced by many customers served by this feeder. A highest mean SAIFI of 0.1931 with a standard deviation of 0.0686 were recorded on Shell 3 feeder of the distribution system even though a highest value of SAIFI standard deviation was recorded on Shell 1 feeder of the distribution system as shown in Figures 9 and 10

Many of the customers were interrupted on this feeder while few of them were adequately served. The least mean SAIFI of 0.1392 , and a standard deviation of 0.0198 were also recorded.. Many of the customers attached to this feeder were adequately served.

Airport feeder recorded the highest mean CAIDI of 0.7651 and a standard deviation of 0.3989 as shown in Figures 11 and 12. This is because customers on this feeder were interrupted for a prolonged time even though, the number of customer interruption had reduced accordingly.

Michelin feeder has the least mean CAIDI of 0.3813 with a standard deviation of 0.2636 . This is because fewer of the customers attached to this feeder were interrupted for a short time.

\section{Conclusion}

The statistical analysis of reliability indices of selected distribution systems on the national grid system has been presented. Olowu feeder of Ikeja distribution system recorded the highest mean SAIDI of 01040 compared to all other feeders in the selected distribution system. Customers on this feeder were interrupted for a prolonged time while fewer of the customers were adequately served. 7-UP feeder of Ikeja distribution system had the least mean SAIDI of 0.0693 because customers' interruption was for a short period of time even though; more customers were being served by the feeder.

Airport of Port-Harcourt recorded the highest mean SAIDI of 0.1050. More customers were interrupted compared to all other feeders on the distribution system while fewer of them served adequately served. Airport feeder of Port Harcourt distribution system had a least mean SAIFI of 0.1392 because fewer of the customers attached to this feeder were interrupted while many of them were adequately served. 




Figure 1: Mean SAIDI for Ikeja distribution systems

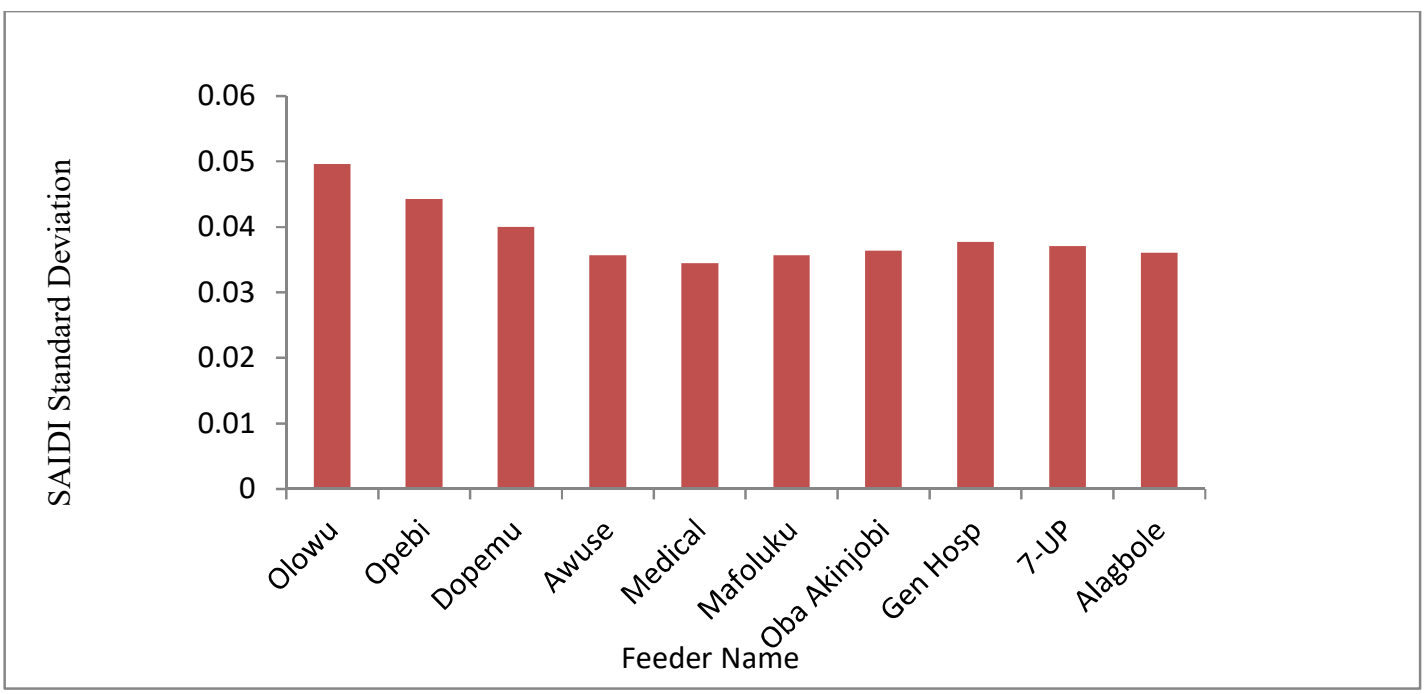

Figure 2: Standard Deviation of SAIDI for Ikeja distribution systems 


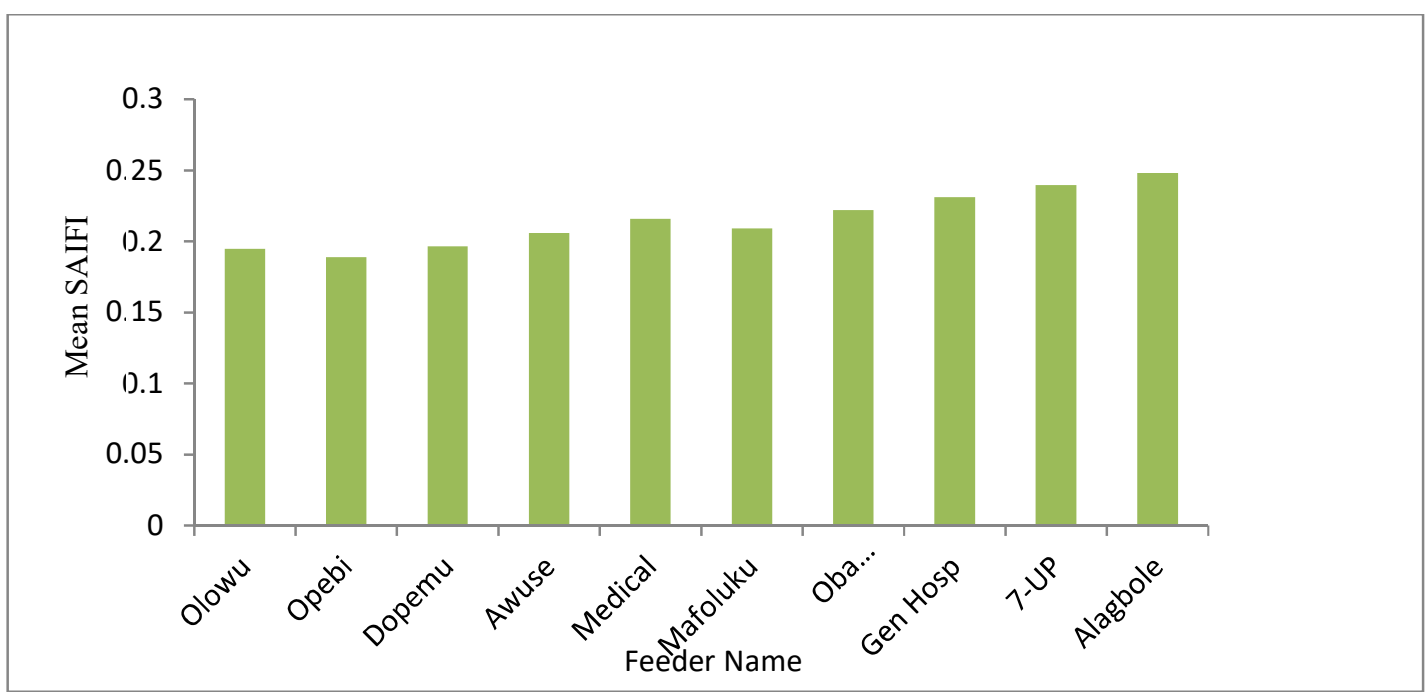

Figure 3: Mean SAIFI for Ikeja distribution systems

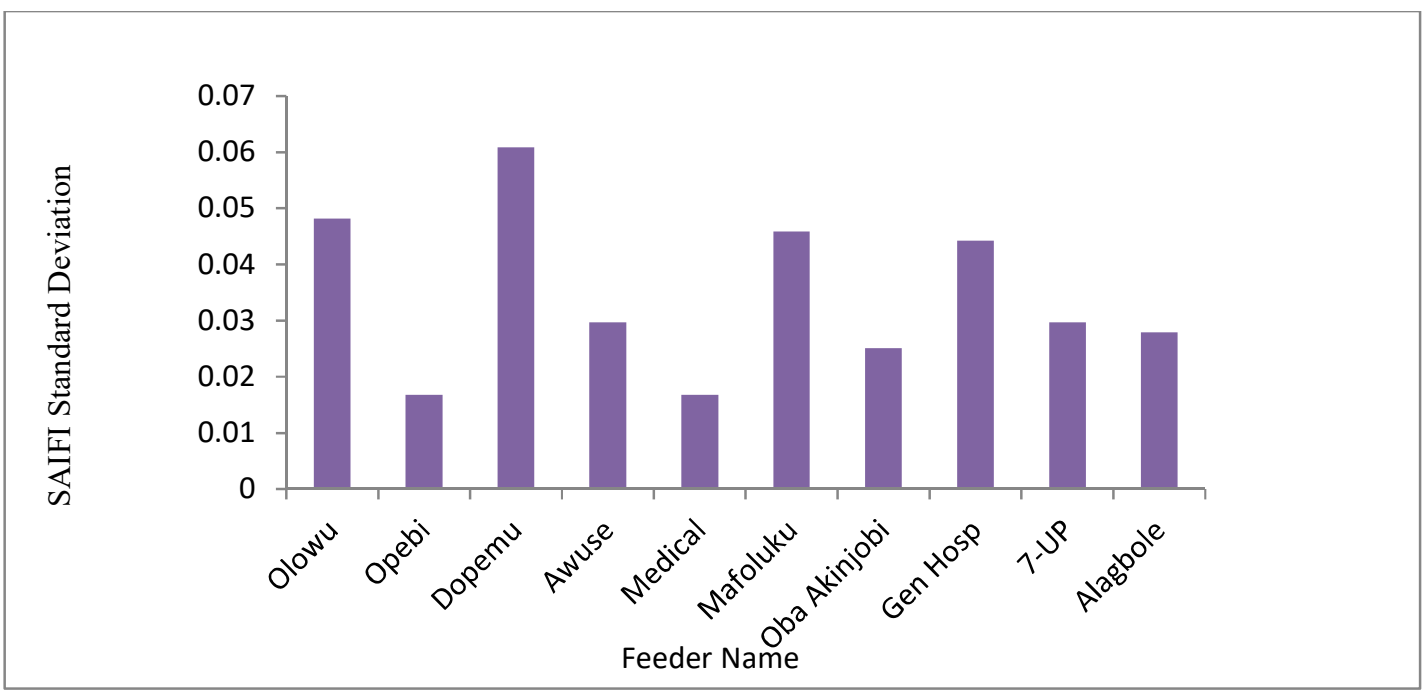

Figure 4: Standard Deviation of SAIFI for Ikeja distribution systems 




Figure 5: Mean CAIDI for Ikeja distribution systems

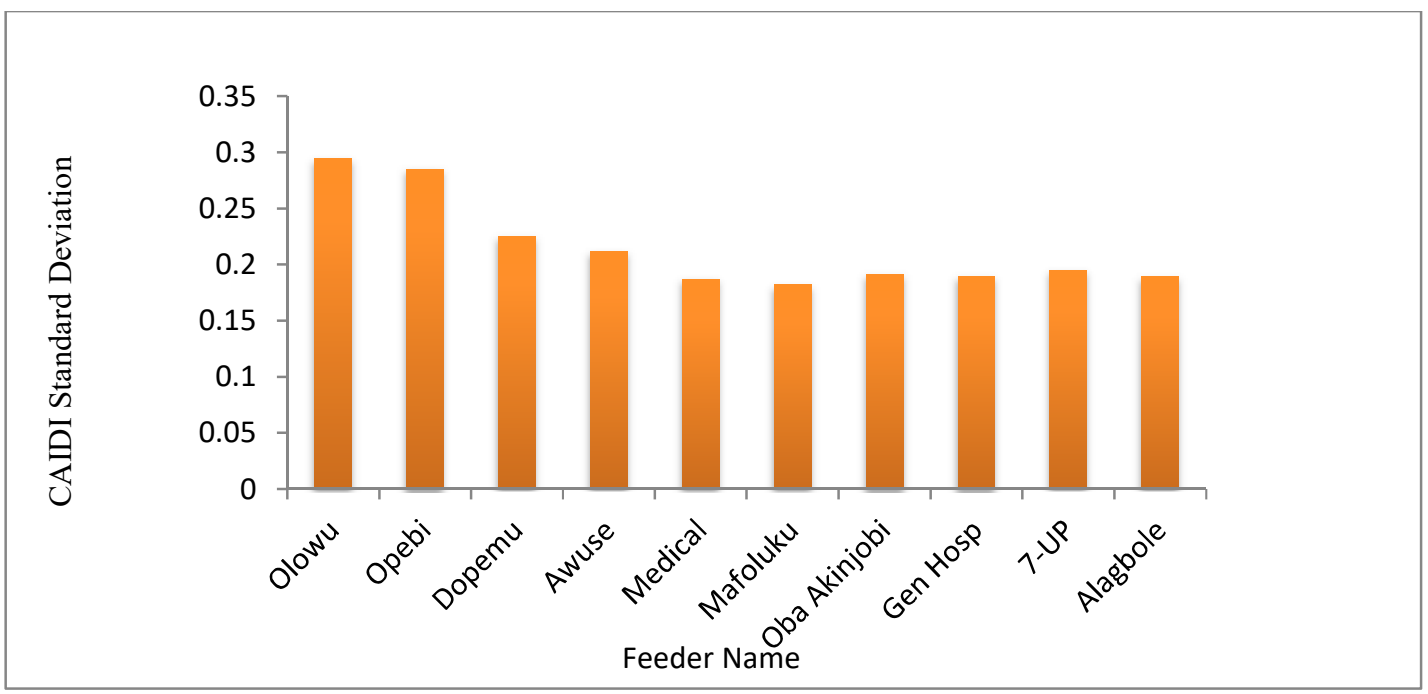

Figure 6: Standard Deviation of CAIDI for Ikeja distribution system 




Figure: 7: Mean SAIDI for Portharcourt distribution systems.

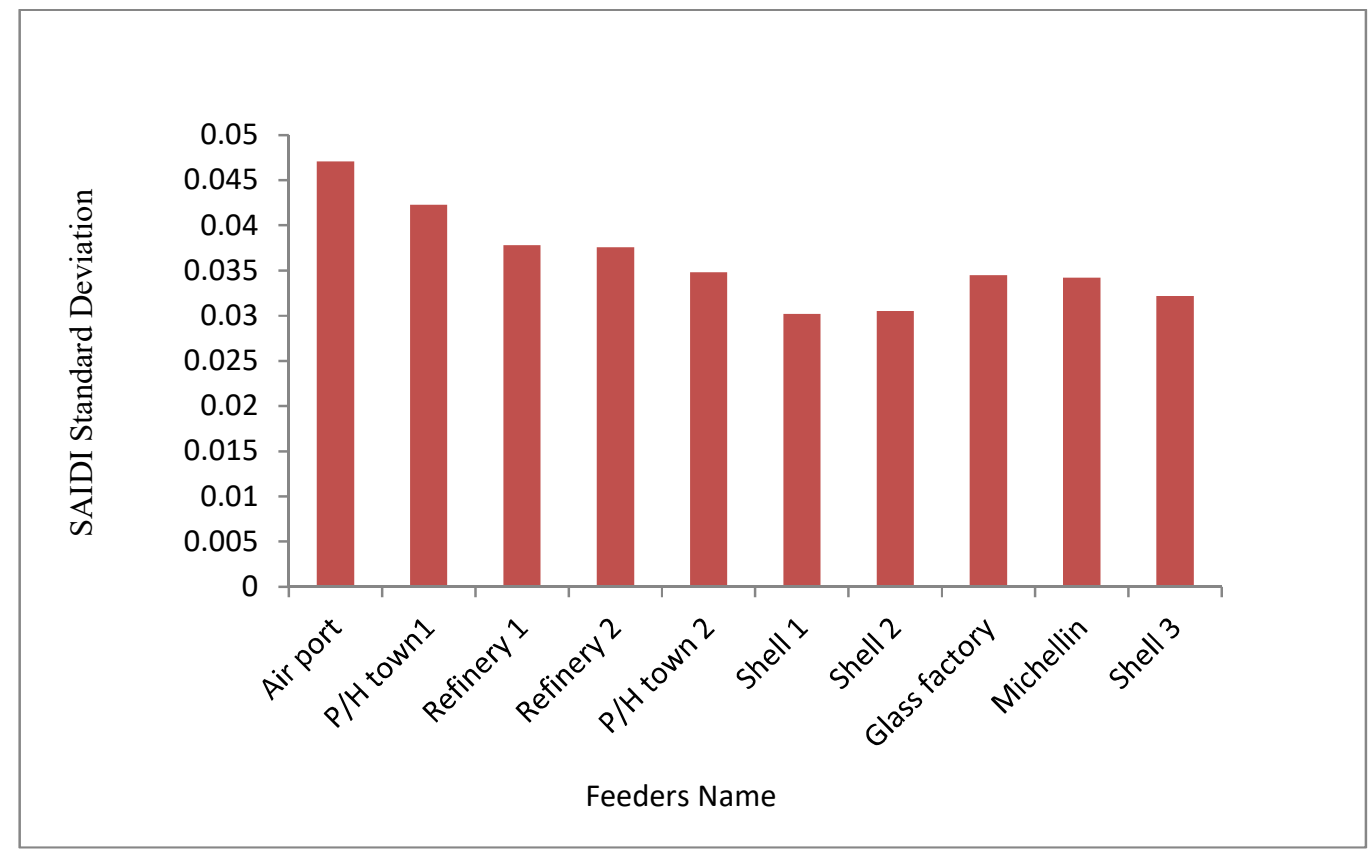

Figure 8: SAIDI standard deviation of Portharcourt distribution systems. 




Figure 9: Mean SAIFI for Portharcourt distribution systems.

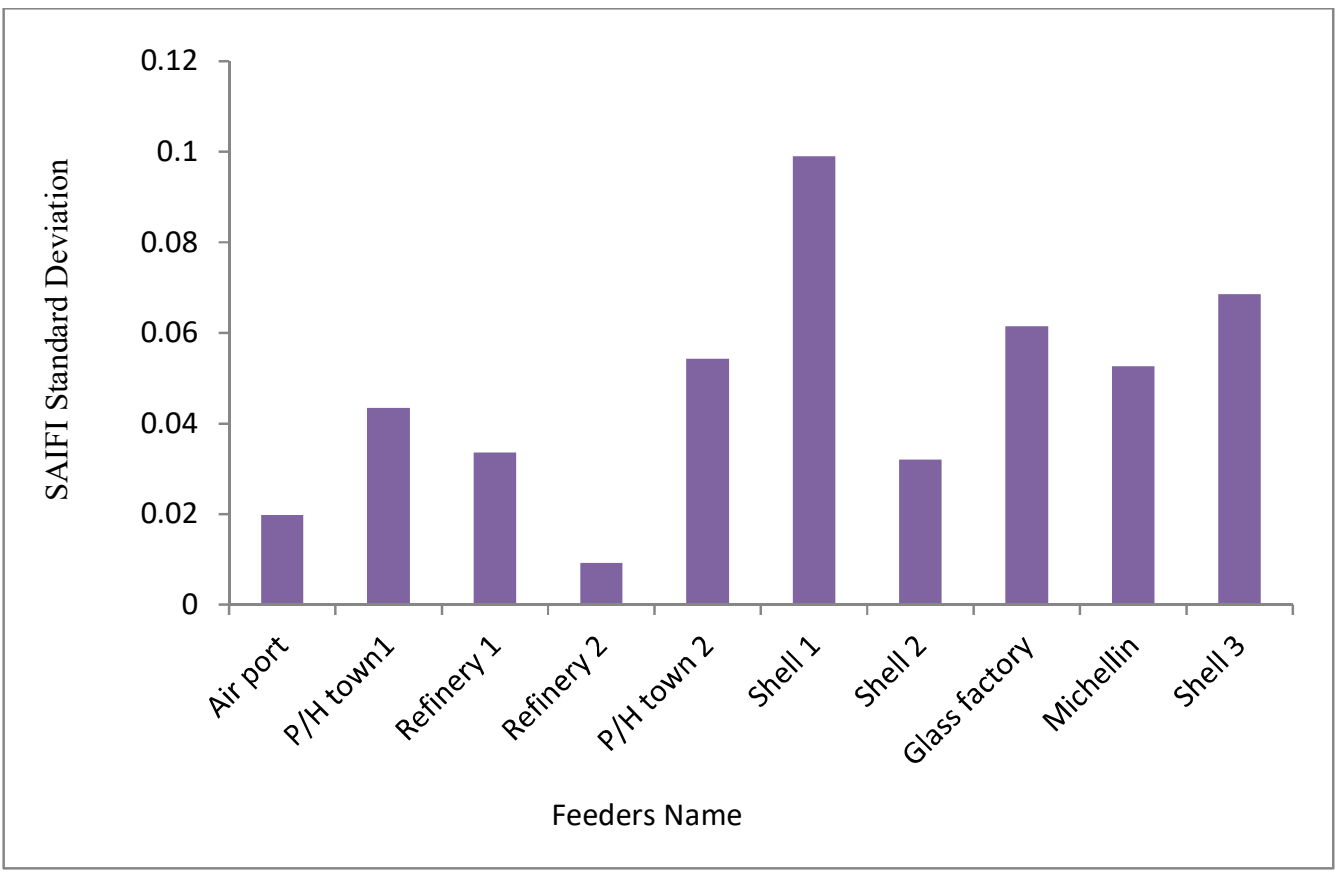

Figure 10: SAIFI standard deviation of Portharcourt distribution systems. 


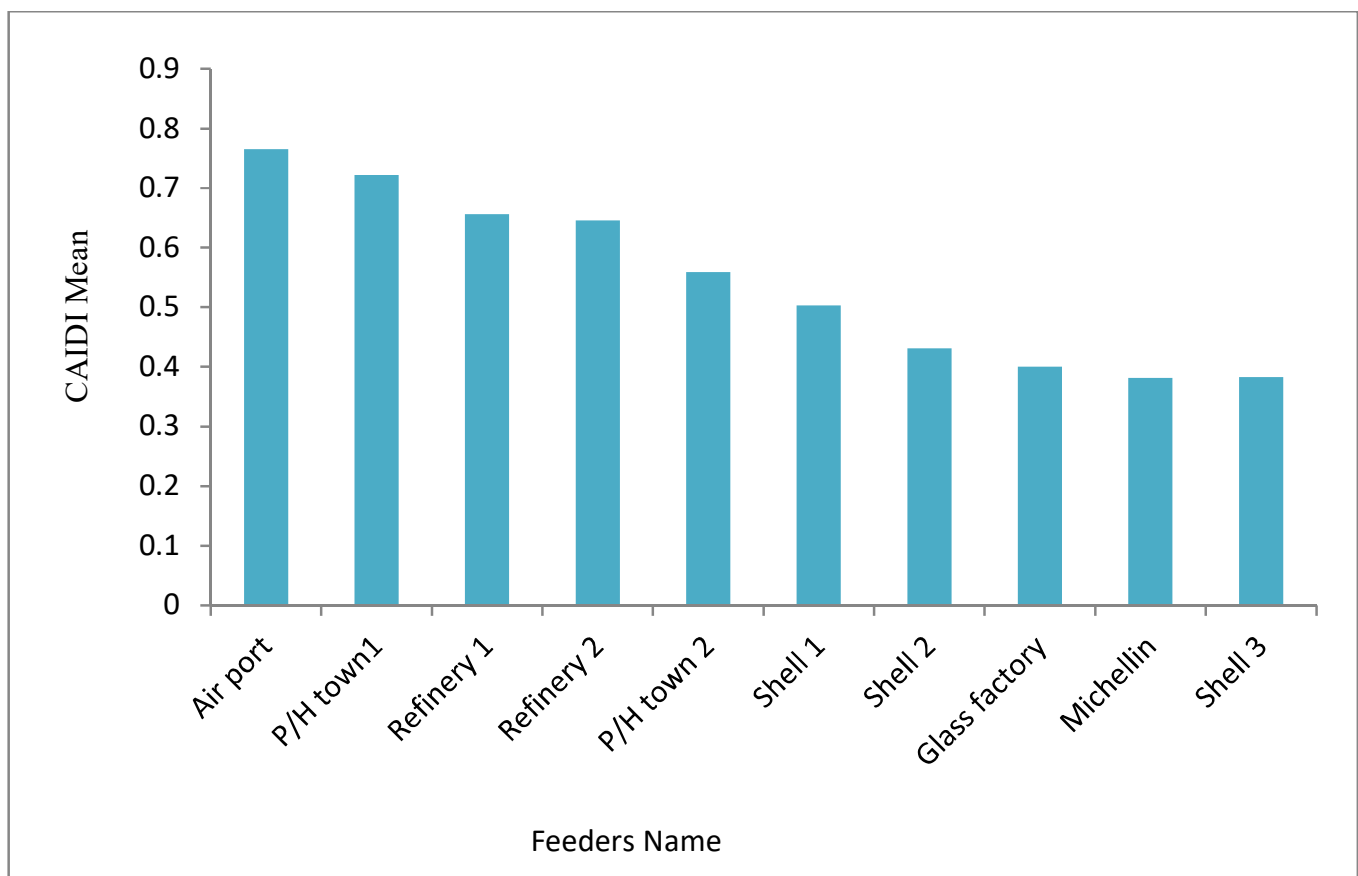

Figure 11: Mean CAIDI for Portharcourt distribution systems.

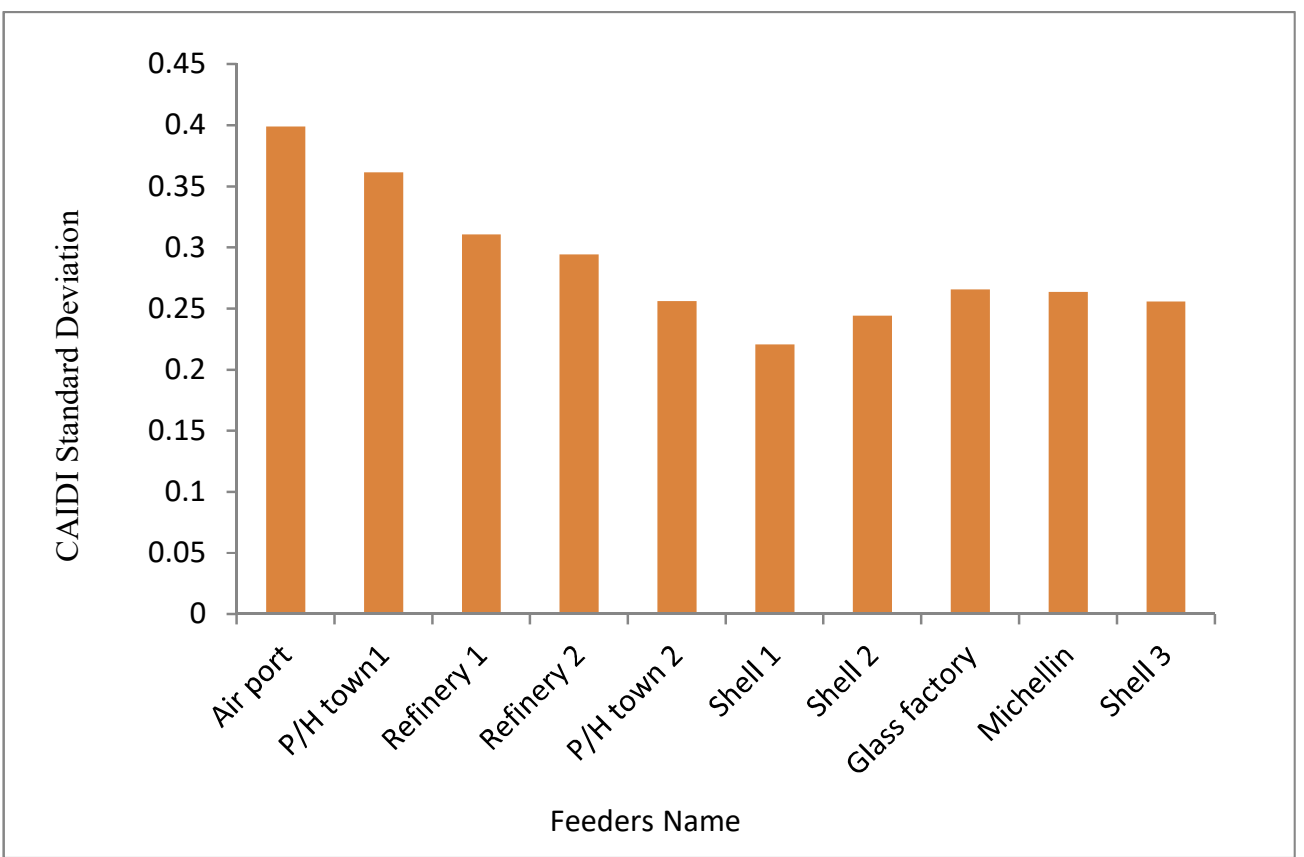

Figure 12: CAIDI standard deviation of Portharcourt distribution systems. 


\section{References.}

Allen W. J. and Bruce W. F. (2013): "Power Generation, Operation and Inc. Fourth Edition, pp. $204-219$.

Control", John Wiley and Sons,

Anderson P. and Bose A, (2003): “A probabilistic approach to power system stability analysis”, IEEE Transactions on Power Apparatus and Systems, Vol. PAS - 102, $\quad$ Pp. 2430-2439.

Andreotti A., Assante D, Mottola F and Verolino L. (2009): “An exact closed-form solution for lightning induced over voltage calculations", IEEE transactions on power system, Vol. 24, No. 3, Pp 1328-1343.

Applebaum S. P. (2010): “Transient Stability approach for reliability studies”. John Wiley and Sons Inc., Third Edition, pp 31-38.

Billinton (2010):“A mathematical model for reliability assessment of distribution system using statistical analysis.," IEEE Transactions on Power Systems. Vol.9, No. 3, pp. 228 - 233.

Billinton R. and Khan E. (2008): “A security based approach to composite power system reliability evaluation." IEEE Transactions on Power Systems. Vol.7, No. 1, pp. 258 - 263.

Billinton (2014):“A probabilistic technique for assessment of operating reserves in power systems," IEEE Transactions on Power Systems. Vol.7, No. 5, pp. 128 - 138.

Billinton, R. and Singh, C. (2004): "System load Representation in Generating Capacity Reliability Studies". The Nigerian Engineer, Vol. 19, No 1. Page 14-19.

Billinton R and Wang P (1999): "Deregulated power system planning using a reliability network equivalent technique proc. IEEE Generation, Transmission and distribution”, Vol. 14, No. 1, pp. 25-30.

Cyman, W.J. (2002); “Calculating probability of generating capacity outages". IEEE Transactions on Power Systems. Vol. 66, No. 9, Pp $1471-1477$.

Elena, N. Z and Vitaly G. L. (2006): "Design of dynamic reliability indices". IEEE Transactions on power systems, vol. 18, No. 5. pp 39-51

El-Kady M. A, Alaskar B. A, Shaalan A. M, and Al-Shammri B.M (2007): "Composite reliability and quality assessment of interconnected power systems”. IEEE Transactions on Power Systems, Vol. 11, No. 5, pp 328-396.

Endrenyi J. and Anders G. J. (2006): “Aging maintenance and reliability”, IEEE Power energy magazine, Vol. 4, No. 3, pp 59-67.

Farag y, Gold R and Minter t(2008):“A new probabilistic reliability assessment framework for power systems.," IEEE Transactions on Power Systems. Vol.2, No. 2, pp. $321-336$.

Mitra Y and Singh T (2016) :"D.C load flow model in power distribution system," IEEE Transactions on Power Systems. Vol.12, No. 9, pp. $318-321$.

Nagaraj T, Edwin R and Joe W (2014),” IEEE Transactions on Power Systems. Vol.10, No. 2, pp. 317 - 325. 